\title{
Hospitalization among diabetic children and adolescents and non- diabetic control subjects: a prospective population-based study
}

\author{
A. Icks, J. Rosenbauer, B. Haastert, G. Giani \\ Department of Biometrics and Epidemiology, German Diabetes Research Institute, Düsseldorf University, Düsseldorf, Germany
}

\section{Abstract}

Aim/hypothesis. Data comparing the hospitalization of diabetic paediatric patients with the non-diabetic population is scarce. We undertook a populationbased incidence study to compare hospitalization in a cohort of Type I diabetic children and adolescents, in Germany, in the first course of treatment after diabetes onset, with hospitalization in non-diabetic control subjects matched for age, sex, and region.

Methods. A total of 373 subjects with newly diagnosed diabetes (onset between 1 and under 15 $(<15)$ years of age in 1996 and 1997; 54\% male, mean age at diagnosis $7.6 \pm 3.8$ years) and 783 non-diabetic control subjects matched for age, sex, and region were followed for 1 year on average. Hospital admissions and the length of stay (days) were assessed by written questionnaires. Incidence rates of hospitalization and the expected number of hospital days per person-year were estimated for both cohorts. Using Poisson regression, we estimated ratios of hospitalization incidence rates (IRRs) and of ex- pected numbers of hospital days (DRRs) in the diabetic cohort compared to the non-diabetic cohort, adjusting for age, sex and social status.

Results. Hospitalization incidence rates and hospital days, expressed per person-year $(95 \%-\mathrm{CI})$, were $0.34(0.29-0.39)$ and $2.36(2.22-2.50)$ in the diabetic cohort and 0.07 (0.05-0.09) and 0.29 (0.26-0.33) in the non-diabetic cohort, respectively. Among diabetic subjects, both parameters were associated with higher age and female sex. IRR and DRR (95\%-CI) were 4.7 (3.5-6.5) and 7.7 (6.7-8.9).

Conclusion/interpretation. In the first year after onset, children and adolescents with diabetes had a 4.7 times higher hospitalization risk and spent 7.7 times more days in hospital than non-diabetic subjects. The ratios were smaller than those in Finland and Denmark in the 1980 s, most likely due to differences between health care systems and time trends. [Diabetologia (2001) 44 [Suppl 3]: B 87-B 92]

Keywords Diabetes, children, adolescents, hospitalization, population-based study.
Hospitalization in children and adolescents with diabetes is associated with great personal distress and social costs [1-6]. In the United States, diabetes in childhood is one of the 10 leading causes of preventable hospitalization in people aged under 18 years of age [7]. A reduction of hospitalization is one of the

Corresponding author: A. Icks MD, MPH, German Diabetes Research Institute, Department of Biometrics and Epidemiology, Auf'm Hennekamp 65, D-40225 Düsseldorf, Germany Abbreviations: IRR, Incidence rate ratio; DRR, day rate ratio (ratio of expected number of hospital days per person per year). main goals of the declarations of St. Vincent and Kos for the structured treatment of childhood diabetes and it will be a major indicator of diabetes quality management [8-13].

Hospitalization in general differs between countries and time periods. Among diabetic children as well as non-diabetic children, hospitalization rates are much higher in European countries than in the United States [14-17]. In Germany, the average length of a stay in hospital per admission decreased from 20 to 11 days between 1980 and 1997 [18]. Therefore, the relative hospitalization risk for diabetic children and diabetic adolescents compared with 
non-diabetic subjects could be a useful additional parameter to describe the excess risk of hospitalization due to diabetes. However, little information is available on the situation for children and adolescents with Type I (insulin-dependent) diabetes mellitus, especially from population-based studies.

Our study estimated the excess hospitalization risk and duration in a population-based cohort of children and adolescents with Type I diabetes onset, between 1 and under 15 years of age, compared with non-diabetic control subjects, matched for age, sex, and region, and the association between hospitalization and age, sex, and social status in diabetic subjects. The study was carried out in North-Rhine-Westfalia, a federal state of Germany with about 18 million inhabitants, representing $23 \%$ of the German population. The cohort was followed on average for one year after diabetes onset. This early period of treatment has been reported to be very expensive due to hospitalization [5].

\section{Subjects, material and methods}

Diabetic subjects. For a population-based incidence study in North-Rhine-Westfalia, a total of 811 subjects with Type I diabetes between 1 and under $(<) 15$ years of age were assessed between 1996 and 1997. This study was an extension of a population-based incidence study in the Düsseldorf region, which is part of the EURODIAB TIGER network [19]. At diabetes onset, a postal questionnaire was sent by the paediatric departments to 647 of the 811 families with a diabetic child to assess the relevant demographic variables. About one year after diabetes onset, a second questionnaire was sent out to assess all hospitalizations after diabetes onset. A total of 416 families returned both questionnaires, constituting $51 \%$ of all incident cases between 1996 and 1997. Altogether 43 cases were excluded because no control subject was available. Finally, 373 cases (46\% of all incident cases in 1996/1997) went into further analyses. Participating children and adolescents were similiar to non-participants with respect to age, sex, and the size of the paediatric department in which the diabetes was diagnosed.

Control subjects. For each diabetic subject that returned the first questionnaire, up to six families living in the same district with a child or adolescent having the same sex and same age ( \pm 3 months) were identified by the local register offices and asked to participate in the study. A total of 2238 families were contacted who had children with similar characteristics as the 373 diabetic study subjects. Two questionnaires (same questionnaires and procedures as for the diabetic subjects) were sent out. In total, 783 responded to both questionnaires, constituting $33 \%$ of the targeted control families. Diabetes was excluded by self-reporting of the families in the questionnaire.

Variables. Gender, date of birth, and residence was recorded for each study subject. Social status was defined according to the educational level of parents.

Hospital stays, defined as at least one night in a clinic, were documented including date of admission, length of stay (number of days including day of admission and discharge) and cause of admission. Admission at diabetes onset was not included in the analysis.
The follow-up period was defined as the time between diabetes onset (defined as date of first insulin injection) and the second questionnaire in children and adolescents with diabetes, and the time between the first and the second questionnaire in control subjects. For the analyses, the observation period was limited to 1.5 years.

Statistical methods. First, descriptive statistics were performed for all continuous and categorial variables. Differences were tested using two-sided $t$-tests or chi-squared tests where appropriate. A $p$ value of less than 0.05 was considered to be statistically significant.

Frequencies of hospitalization were estimated as rates per person-year in the diabetic and in the non-diabetic cohort, assuming Poisson distribution [20]. Hospitalization incidence rate ratios (IRRs), adjusted for age (age groups $1-<5,5-<10$, $10-<15$ years of age), sex, and social status (categories: $\leq 10$ or missing, $>10$ years school education) were calculated using Poisson regression models. Results for the length of hospital stay are given as hospital days per person per year. To compare hospital duration in the diabetic with the non-diabetic cohort, adjusted ratios of expected numbers of hospital days per person-year (DRRs) were determined, applying multivariate Poisson regression with covariates age, sex, and social status. Furthermore, the influence of age, sex, and social status on hospitalization among diabetic subjects was estimated.

All analyses were performed with the Statistical Analysis System (SAS) Version 6.12 TS 020 software programme (SAS Institute, Cary, N. C., USA).

\section{Results}

Subjects' characteristics. The mean follow-up periods (range) were $1.2(0.6-1.5)$ and $1.1(0.6-1.5)$ years in the diabetic and the non-diabetic cohort, respectively. As expected from matching, mean age and gender distribution were similiar in diabetic and in non-diabetic subjects (mean age: $p=0.34$; sex: $p=0.87$ ). The proportion of subjects with a higher school education ( $>10$ years) was significantly lower in diabetic than in non-diabetic subjects $(43.2 \%$ compared to $54.4 \%$, $p<0.01)$ (Table 1).

Hospitalization. In the diabetic cohort, 151 hospital admissions and 1046 hospital days were reported in the study period. In the non-diabetic control cohort, there were 58 hospital admissions and 248 hospital days. Among diabetic subjects, $33.5 \%$ were hospitalized at least once in the follow-up-period and $5.9 \%$ more than once. In non-diabetic subjects, the respective proportions were $6.9 \%$ (at least one admission) and $0.5 \%$ (more than one admission). Mean length $( \pm \mathrm{SD})$ of hospital stays was $6.9( \pm 5.8)$ days and 4.3 $( \pm 3.2)$ days in diabetic and in non-diabetic subjects, respectively.

The highest proportion of admissions in diabetic subjects $(n=61,41.2 \%)$ could be attributed to the participation in a structured (individual or group) educational programme. Altogether 15 hospital stays $(10.1 \%)$ were due to acute complications (severe hy- 
Table 1. Sex, age and social status of the diabetic and non-diabetic study cohort

\begin{tabular}{lll}
\hline & $\begin{array}{l}\text { Diabetic } \\
\text { subjects } \\
(n=373)\end{array}$ & $\begin{array}{l}\text { Non-diabetic } \\
\text { subjects } \\
(n=783)\end{array}$ \\
\hline $\begin{array}{l}\text { Sex (\% male) } \\
\begin{array}{l}\text { Age at study onset } \\
\text { (years: mean } \pm \text { SD, range) }\end{array}\end{array}$ & 54.2 & 54.7 \\
$\begin{array}{l}\text { Parents' school education } \\
\text { highest degree, } \% \\
\text { no certificates }\end{array}$ & $7.6 \pm 3.8 ; 1-14$ & $7.4 \pm 3.8 ; 1-14$ \\
$\begin{array}{l}\text { elementary } \\
(9 \text { or } 10 \text { years in school) } \\
\text { high school qualification } \\
(>10 \text { years) }\end{array}$ & $53.9 \%$ & $4.0 \%$ \\
\hline
\end{tabular}

a including $n=12$ missing

poglycaemia or ketoacidosis), 38 (25.7\%) due to metabolic control. A total of $23 \%$ of admissions were due to other reasons, including admissions unrelated to diabetes.

The hospitalization incidence rates per personyear were 0.34 (95\% -CI 0.29-0.39) in the diabetic cohort and 0.07 (95\%-CI 0.05-0.09) in the non-diabetic cohort. The number of hospital days per person-year were $2.36(95 \%$-CI $2.22-2.50)$ and $0.29(95 \%-C I$ $0.26-0.33)$ in the diabetic and in the non-diabetic group, respectively. Direct standardization to the population of North-Rhine-Westfalia with respect to age and sex yielded nearly exact the same estimates (data not shown).
Multivariate analyses. In the multivariate Poisson regression model analysis (Table 2), the hospitalization incidence rate ratio for the diabetic subjects compared with the non-diabetic subjects adjusted for age, sex, and social status was 4.7 (95\%-CI: 3.5-6.5). The adjusted ratio of the expected numbers of hospital days was 7.7 (CI: 6.7-8.9). A higher social status was significantly associated with a lower hospitalization rate as well as with a lower number of hospital days, adjusted for diabetes, age and sex. Furthermore, female sex and higher age $(5$ to $<10,10$ to $<15$ years vs 1 to $<5$ years) was significantly associated with an increased number of hospital days, but not with an increased hospitalization rate.

Among diabetic subjects, higher age, female sex and lower social status were significantly associated with an increased number of hospital days in the multivariate regression model but not with an increased hospitalization rate (Table 3 ).

\section{Discussion}

The aim of this population-based study was to compare hospitalization in diabetic children and adolescents in the first course of treatment after diabetes onset, with hospitalization in non-diabetic subjects, matched for age, sex and region, in the largest federal state of Germany between 1996 and 1997. The control group of non-diabetic subjects was needed to estimate the relative hospitalization risk, which was less sensitive to differences in gen-

Table 2. Influence of diabetes, age, sex, and social status on hospitalization rates and days (multivariate Poisson regression analysis)

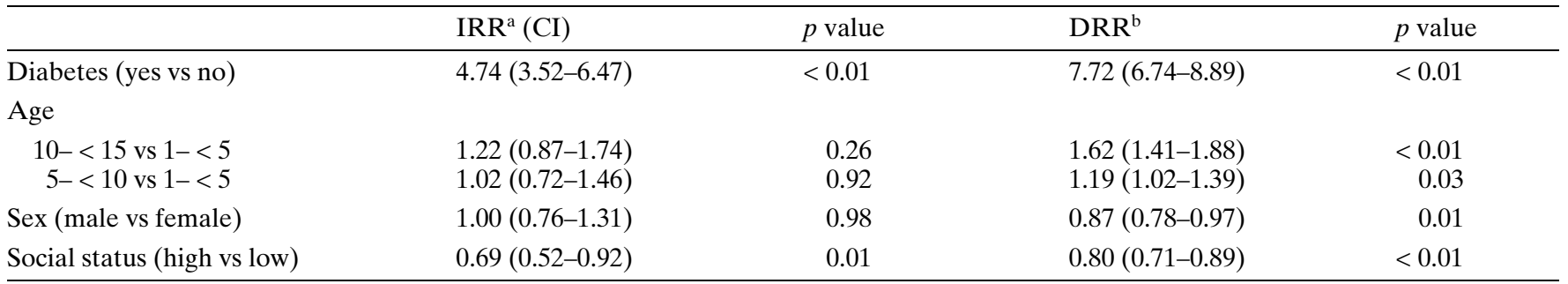

${ }^{a}$ ratio of hospitalization incidence rates

${ }^{\mathrm{b}}$ ratio of expected numbers of hospital days per person-year

Table 3. Influence of age, sex, and social status on hospitalization rates and days in diabetic subjects (multivariate Poisson regression analysis)

\begin{tabular}{|c|c|c|c|c|}
\hline & $\operatorname{IRR}^{\mathrm{a}}(\mathrm{CI})$ & $p$ value & $\mathrm{DRR}^{\mathrm{b}}$ & $p$ value \\
\hline \multicolumn{5}{|l|}{ Age } \\
\hline $\begin{array}{r}10-<15 \text { vs } 1-<5 \\
5-<10 \text { vs } 1-<5\end{array}$ & $\begin{array}{l}1.50(1.00-2.29) \\
1.00(0.65-1.57)\end{array}$ & $\begin{array}{l}0.05 \\
0.98\end{array}$ & $\begin{array}{l}2.03(1.72-2.41) \\
1.33(1.11-1.59)\end{array}$ & $\begin{array}{l}<0.01 \\
<0.01\end{array}$ \\
\hline Sex (male vs female) & $0.85(0.61-1.17)$ & 0.31 & $0.72(0.64-0.81)$ & $<0.01$ \\
\hline Social status (high vs low) & $0.71(0.50-0.98)$ & 0.04 & $0.75(0.66-0.85)$ & $<0.01$ \\
\hline
\end{tabular}

${ }^{a}$ ratio of hospitalization incidence rates

${ }^{\mathrm{b}}$ ratio of expected numbers of hospital days per person-year 
eral hospitalization between countries and calendar times than hospital incidence itself.

The study showed that children and adolescents with diabetes onset aged between 1 and under $(<)$ 15 years of age had significantly more hospital admissions (4.7 times) and hospital days (7.7 times) in the first period after diagnosis than non-diabetic control subjects. Higher age $(5-<10$ and $10-<15$ years compared to $1-<5$ years) and female sex were significantly associated with an increased number of hospital days, as in the results of a Danish study [23]. A higher social status was significantly related to a lower hospitalization risk and a decreased number of hospital days.

The results are difficult to compare because there are only a few studies reporting relative hospitalization risk in childhood diabetes and none of these studies took diabetes duration into account. In Finland and Denmark in the 1980 s, a 4 to 8 times increased risk for hospitalization and a 10 to 14 times increased number of hospital days was found in paediatric diabetic patients compared with control subjects, that is higher than in the present study [23-25]. This can be explained in part by differences between health care systems. An additional explanation could be connected with the period of the studies (late 1990s vs 1980s), as it can be assumed that hospitalization in diabetic children and adolescents has decreased in the last few years [26].

In two recent clinic-based studies comparing diabetic subjects under 20 years of age in Germany with the general population, the hospital risk ratios were similiar to those observed in the present study, whereas the ratios of hospital days per person-year were lower (3.0 and 3.8) [21, 22]. This can be explained in part by longer hospital stays in the first course of treatment after diabetes onset [14]. However, the most important reason for the higher ratios of hospital days could be the absence of long-stay patients in our study, in particular in the control group (no hospitalization was longer than 31 days), probably due to the number of highly educated families and the absence of "very ill" subjects. This explanation is supported by a simulation which demonstrates the extent to which even a few long-stay patients ("outlier") influence results: adding one diabetic and one non-diabetic subject, each with 90 hospital days per year, yields an adjusted rate of hospital days of 6.4 (5.6-7.2) instead of 7.7.

Among diabetic subjects in our study, pubertal age (10 to under $(<) 15$ years) and female sex were significantly associated with an increased number of hospital days. Interestingly, there was no difference in hospital incidence rates between children between 1 and 5 years of age or under compared with older subjects, as would have been expected. A possible explanation is that structured education, often associated with hospital stays of more than 1 week in Germany, is frequent in school children and pubertal age (5- $<10$ years: $42.6 \%, 10-<15$ years: $55.2 \%$ of hospital admissions), whereas it is less frequent in younger children $(11.8 \%$ of admissions in the age group 1 to under 5 years). As reported in several studies [17, $27,28]$, a higher social status was significantly associated with lower hospitalization.

The hospitalization incidence in diabetic subjects in the present study was similar to those found in centre-based studies using clinical documentation [21, 22], as well as those reported in Great Britain in the first course after onset [14]. However, it was much higher than those from the United States [17, 16]. Nevertheless, in the United States hospitalization in general is much lower than in European countries [24], probably due to differences in the health care systems.

In the present study, a high proportion of hospitalization due to a structured educational programme was observed but low proportions of acute complications as hypoglycaemia and ketoacidosis compared with studies in Great Britain and in the United States, where about one third respective one fifth of hospitalizations were due to severe hypoglycaemia [14, 17]. It is conceivable that structured education in the first course after diabetes onset results in lower complication events and will lead to lower hospitalization in the following [17, 29, 30, 31, 32, 33]. Nevertheless, it has to be discussed whether educational programmes can be performed in outpatient settings.

One of the limitations of this analysis is that the response rate to the follow-up was $51 \%$ of the total number of incident cases in North-Rhine-Westfalia in 1996 and 1997. A total of $33 \%$ of the contacted non-diabetic control families participated in the follow-up. In the control group, highly educated families are overrepresented. As mentioned above, in non-diabetic subjects in particular, long-stay patients were missing, compared with the general German population [18]. Unfortunately, until now, diabetes registers or detailed official hospital statistics are lacking in Germany to complete and validate the data of the present study. However, the diabetic subjects with onset in 1996 and 1997, who participated in the present study, and the diabetic non-participants did not differ in age and sex. Furthermore participants and nonparticipants were diagnosed with diabetes in paediatric department of similar size so that we can assume that the patients are not selected mainly from specialized or tertiary referral diabetes centres. To reduce bias, ratios of hospital rates and days were estimated, adjusting for age, sex and social status. Nevertheless, a selection bias might be present.

Furthermore, hospitalization data was assessed by self-report of the subjects. Because hospitalization is, however, a striking event for families, underreporting due to recall bias is not likely. Furthermore, hospital incidences in our study were in line with a clin- 
ic-based study in diabetic paediatric patients in Germany in 1997 [21].

To summarize, in this population-based study hospitalization in children and adolescents with diabetes in the first course after onset is significantly increased compared with non-diabetic subjects matched for age, sex, and region.

Relative hospitalization risk could be an important additional indicator for quality management because it is less dependent on differences in general inpatient care between health care systems and on changes between time periods due to health policies. A repeat of this study or a system of continuous reporting could ascertain whether a reduction of the excess hospitalization risk in diabetic children, which was declared a main goal of care in childhood diabetes, has occurred. Improvements of care in childhood diabetes is of growing importance because of the discussion about health care expenditure and rising incidence in childhood diabetes [34-38].

Acknowledgements. We are grateful to all physicians, staff of hospitals and practices, and also all families supporting our study. This study was supported by the European Community Concerted Actions EURODIAB ACE (Contract BMH1CT92-0043) and EURODIAB TIGER (Contract BMH4CT96-0577).

\section{References}

1. Gray A, Fenn P, McGuire A (1993) The cost of insulin-dependent diabetes mellitus (IDDM) in England and Wales. Diabet Med 12: 1068-1076

2. Olsson J, Persson U, Tollin C, Nilsson S, Melander A (1994) Comparison of excess costs of care and production losses because of morbidity in diabetic patients. Diabetes Care 17: 1257-1263

3. Triomphe A, Flori Y-A, Lanoë J-L (1993) The costs of diabetes to society and the individual (Chapter 16). In: Williams R, Papoz L, Fuller J (eds) Diabetes in Europe. John Libbey and Company Ltd/Editions INSERM, pp. 153-160

4. Simell T, Simell O, Sintonen H (1993) The first two years of Type I diabetes in children: Length of the initial hospital stay affects costs but not effectiveness of care. Diabet Med 10: $855-862$

5. Simell T, Sintonen H, Hahl J, Simell OG (1996) Costs of insulin-dependent diabetes mellitus. PharmEconom 9: 24-38

6. Gåfvels CM, Lithner FG (1996) Insulin-treated diabetic patients. Use of, experience of and attitudes to diabetes care. Eur J Pub Health 6: 262-269

7. Harms L (1994) Preventable hospitalizations among children in Wisconsin, 1993. Madison: Wisconsin Department of Health and Social Services. Division of Health, Centre for Health Statistics

8. Diabetes care and research in Europe (1989) The Saint Vincent Declaration. World Health Organization: ICP/ CLR 034

9. International Society of Pediatric and Adolescent Diabetes (ISPAD) (1994) Declaration of Kos. Diabetes Young 30: 14

10. American Diabetes Association (1996) Clinical practice and recommendations 1996. Diabetes Care 19 (Suppl 1): $1-118$
11. Chiarelli F, Verrotti A, Di Ricco L, De Martino M, Morgese G (1998) Approaches to quality of control in diabetes care. In: Quality control of diabetes care and chronic complications in young people after St. Vincent and Kos. International Journal of Experimental and Clinical Endocrinology, Horm Res 50 (Suppl): 41-47

12. International Society of Pediatric and Adolescent Diabetes (1995) Consensus Guidelines for the management of insulin-dependent (type I) diabetes mellitus (IDDM) in childhood and adolescents. Copyright by ISPAD and IDF Europe, Freund Publishing House Ltd, London, Tel Aviv

13. British Paediatric Working Party (1990) The organization of services for children with diabetes in the United Kingdom: Report of the British Paediatric Working. Diabet Med 7: 457-464

14. Pinkney JH, Bingley PJ, Sawtell PA, Dunger DB, Gale EAM, The Bart's Oxford Study Group (1994) Presentation and progress of childhood diabetes mellitus: a prospective population-based study. Diabetologia 37: 70-74

15. Faich GA, Fishbein HA, Ellis SE (1987) The epidemiology of diabetic acidosis: a population-based study. Am J Epidemiol 117: 551-558

16. Fishbein HA, Faich GA, Ellis SE (1982) Incidence and hospitalization patterns of insulin-dependent diabetes mellitus. Diabetes Care 5: 630-633

17. Palta M, LeCaire T, Daniels K, Shen G, Allen C, D'Alessio D for the Wisconsin Diabetes Registry (1997) Risk factors for hospitalization in a cohort with Type I diabetes. Am J Epidemiol 146: 627-636

18. Federal Statistical Office (eds) (1998) Health Report for Germany. Metzler-Poeschel, Stuttgart

19. Green A, Gale EAM, Patterson CC on behalf of the EURODIAB ACE Study Group (1992) Incidence of childhood-onset insulin-dependent diabetes mellitus: the EURODIAB ACE study. Lancet 339: 905-909

20. Breslow NE, Day NE (1987) Statistical methods in cancer research, Volume II: The design and analysis of cohort studies. International Agency for Research of Cancer, Oxford University Press

21. Icks A, Rosenbauer J, Holl RW, Grabert M, Rathmann W, Giani G (2001) Hospitalization among diabetic children and adolescents and the general population in Germany. Diabetes Care 24: 435-440

22. Icks A, Rosenbauer J, Schimmel U, Giani G (1999) Hospitalization in children and adolescents with Type I diabetes and in the general population in Germany. Reader of the 15th Annual Scientific Meeting of the International Epidemiology Association (Suppl) (Abstract)

23. Green A, Solander F (1984) Epidemiological studies of diabetes in Denmark: 6. Use of hospital services by insulintreated patients. Diabetologia 26: 195-198

24. Aro S, Kangas T, Reunanen A, Salinto M, Koivisto V (1994) Hospital use among diabetic patients and the general population. Diabetes Care 17: 1320-1329

25. Kangas T (1996) The FinnDiab Report. Health care of people with diabetes in Finland. Stakes Research Report 58

26. Hirasing RA, Reeser HM, DeGroot RRM, Ruwaard D, VanBuuren S, Verloove-Vanhorick SP (1996) Trends in hospital admission among children aged 0-19 years with Type I diabetes in the Netherlands. Diabetes Care 19: 431-434

27. Lloyd CE, Becker D, Ellis D, Orchard TJ (1996) Incidence of complications in insulin-dependent diabetes mellitus: A survival analysis. Am J Epidemiol 143: 431-441

28. Kovacs M, Charron-Prochownik D, Obrosky DS (1995) Longitudinal study of biomedical and psychosocial predic- 
tors of multiple hospitalization among children with Type I diabetes mellitus. Diabet Med 12: 142-148

29. Delamater AM, Bubb J, Davis SG et al (1990) Randomized prospective study of self-management training with newly diagnosed diabetic children. Diabetes Care 13: 492-498

30. Dorchy H, Roggemans M-P, Willems D (1997) Glycated haemoglobin and related factors in diabetic children and adolescents under 18 years of age: a Belian experience. Diabetes Care 20: 2-8

31. Hamman RF, Cook M, Keefer S et al (1985) Medical care patterns at the onset of insulin-dependent diabetes mellitus: association with severity and subsequent complications. Diabetes Care 8: 94-100

32. Simell T, Kaprio EA, Mäënpää J, Tuominen J, Simell O (1991) Randomized prospective study of short-term and long-term initial stay in hospital by children with diabetes mellitus. Lancet 337: 656-660
33. Miller LV, Goldstein J (1997) More efficient care of diabetic patients in a county hospital setting. N Engl J Med 286: 1388-1399

34. Onkamo P, Väänänen S, Karvonen M, Tuomiletho J (1999) Worldwide increase in incidence of Type I diabetes - the analysis of the data on the published incidence trends. Diabetologia 42: 1395-1403

35. Bingley PJ, Gale EAM (1989) Rising incidence of IDDM in Europe. Diabetes Care 12: 289-295

36. Rosenbauer J, Icks A, Giani G (1998) Is the public health impact of Type I diabetes in childhood and adolescents underestimated in Germany? Diabetologia 40(1): A173 (A)

37. Rosenbauer J, Herzig P, Giani G (1999) Temporal, seasonal, and geographical incidence patterns of Type I diabetes mellitus in children under 5 years of age in Germany. Diabetologia 41: 1055-1059

38. Neu A, Kehrer M, Hub R, Ranke MB (1998) Incidence of IDDM in German children aged $0-14$ years. Diabetes Care 20: 530-533 